\title{
The influence of bilateral internal mammary arteries on short- and long-term outcomes: A propensity score matching in accordance with current recommendations
}

\author{
Umberto Benedetto, MD, PhD, Mohamed Amrani, MD, PhD, FETCS, Jullien Gaer, MD, FRCS(C-Th), \\ Toufan Bahrami, MD, Fabio de Robertis, MD, André R. Simon, MD, and Shahzad G. Raja, MRCS, FRCS(C-Th), \\ on behalf of the Harefield Cardiac Outcomes Research Group
}

\begin{abstract}
Objectives: We undertook a single-center, 12 years outcomes analysis of the influence of bilateral internal mammary arteries (BIMA) over single internal mammary artery (SIMA) on short-term outcomes and long-term outcomes by means of propensity score matching technique in accordance to current recommendations.

Methods: A propensity score was generated for each patient from a multivariable logistic regression model based on 20 pretreatment covariates. The study population consisted of 4195 patients undergoing coronary artery bypass graft procedure using SIMA $(\mathrm{n}=3445 ; 78.3 \%)$ or BIMA $(\mathrm{n}=750 ; 21.7 \%)$. A total of 750 matching sets were derived.

Results: The BIMA group was associated with an increased rate of superficial sternal wound infection (5.6\% vs $1.7 \% ; P=.0001)$ but the incidence of deep sternal wound infection was comparable between the 2 groups, at $2.1 \%$ and $1.5 \%$ in BIMA and SIMA groups, respectively $(P=.43)$. With regard to other postoperative complications the 2 groups were comparable. Operative mortality rate did not significantly differ between the 2 groups, at $0.7 \%$ and $1.2 \%$ in the BIMA and SIMA groups, respectively $(P=.28)$. After a mean follow-up time of $4.8 \pm 3.2$ years, BIMA use was associated with a significantly lower risk for late mortality (hazard ratio, $0.61 ; 95 \%$ confidence interval $0.38-0.97 ; P=.03$ ) and need for repeat revascularization (hazard ratio, $0.75 ; 95 \%$ confidence interval, $0.53-0.96 ; P=.03$ ).
\end{abstract}

Conclusions: When compared with SIMA grafting, BIMA use did not increase operative morbidity and mortality and was associated with a better long-term survival. (J Thorac Cardiovasc Surg 2014;148:2699-705)

The use of bilateral internal mammary arteries (BIMA) compared with single internal mammary artery (SIMA) use has been proposed to improve late survival in patients undergoing coronary artery bypass graft $(\mathrm{CABG})$ procedure. ${ }^{1}$ This survival advantage from BIMA use is currently supported by several observational cohort studies ${ }^{2}$ because the only randomized controlled trial to date evaluating long-term survival and freedom from reintervention from BIMA is still ongoing. ${ }^{3}$ However observational studies often have several methodologic flaws that limit the usefulness of their conclusions. ${ }^{4}$

Propensity score (PS) matching, which creates groups of patients who have similar pretreatment characteristics when treatment assignment is not random, has emerged as the most effective statistical method to reduce bias in treatment

\footnotetext{
From the Department of Cardiac Surgery, Harefield Hospital, London, United Kingdom.

Disclosures: Authors have nothing to disclose with regard to commercial support.

Received for publication April 22, 2014; revisions received Aug 9, 2014; accepted for publication Aug 11, 2014; available ahead of print Sept 22, 2014.

Address for reprints: Umberto Benedetto, MD, PhD, Department of Cardiac Surgery, Harefield Hospital, London, UB9 6JH, United Kingdom (E-mail: umberto. benedetto@hotmail.com).

$0022-5223 / \$ 36.00$

Copyright (C) 2014 by The American Association for Thoracic Surgery

http://dx.doi.org/10.1016/j.jtcvs.2014.08.021
}

comparisons in observational studies. ${ }^{5-7}$ With regard to BIMA use, only 4 out of 27 observational studies included in a recent systematic review ${ }^{2}$ using PS matching demonstrated a survival benefit from BIMA. ${ }^{8-11}$ Moreover surgeons continue to be reluctant to use BIMA routinely because concerns still exist regarding the detrimental effect of this strategy on operative outcomes, ${ }^{12}$ including the increased risk for sternal wound complications. ${ }^{13}$ Therefore there is an urgent need for additional well-conducted studies to validate the safety and efficacy of BIMA grafting and enhance its universal adoption.

Recently general recommendations have been proposed in conducting PS matching. ${ }^{5-7}$ We undertook a singlecenter, 12 years outcomes analysis using the PS matching technique in accordance with current recommendations to evaluate the influence of BIMA over SIMA on short- and long-term outcomes.

\section{METHODS}

\section{Study Population}

The study was conducted in accordance with the principles of the Declaration of Helsinki. The local ethics committee approved the study, and the requirement for individual patient consent was waived. We retrospectively analyzed prospectively collected data from an institutional surgical database (Dendrite Clinical Systems, Ltd, Oxford, UK) from April 2001 to May 2013. The database captures detailed information on a wide 

Abbreviations and Acronyms
BIMA $=$ bilateral internal mammary arteries
$\mathrm{CABG}=$ coronary artery bypass graft
DWSI $=$ deep sternal wound infection
LAD $=$ left anterior descending
LVEF $=$ left ventricular ejection fraction
PCI = percutaneous coronary intervention
PS = propensity score
PVD = peripheral vascular disease
SIMA $=$ single internal mammary artery
SSWI = superficial sternal wound infection
SVG = saphenous vein grafts

range of preoperative, intraoperative, and hospital postoperative variables (including complications and mortality) for all patients undergoing CABG in our institution. The data is collected and reported in accordance with the Society for Cardiothoracic Surgery in Great Britain \& Ireland database criteria. The database is maintained by a team of full-time clinical information analysts who are responsible for continuous prospective data collection as part of a continuous audit process. Data collection is validated regularly. Information about death from any cause is regularly obtained from the General Register Office approximately 1 week after the event and data on repeat revascularization is collected from a national surgical and interventional database.

Patients included in the final analysis met the following criteria: first-time isolated $\mathrm{CABG}, \geq 2$ grafts received, and surgical strategies included single left internal mammary artery to left anterior descending (LAD) artery and additional saphenous vein grafts (SVG) for non-LAD targets (SIMA group) or BIMA with or without additional SVG (BIMA group). Internal mammary arteries were harvested as pedicled or skeletonized conduit according to surgeon preference. Antibiotic prophylaxis included $2 \mathrm{~g}$ cefazolin administrated intravenously between 20 to 30 minutes after the induction of anesthesia, followed by $1 \mathrm{~g}$ every 8 hours for 24 hours. For all interventions lasting $>3$ hours, a new dose of $1 \mathrm{~g}$ cefazolin was administered. All patients had strict blood glucose control according to a unique intravenous insulin therapy protocol. The target blood glucose was 100 to $139 \mathrm{mg} / \mathrm{dL}(5.5-7.7 \mathrm{mmol} / \mathrm{L})$. Blood glucose monitoring began upon the arrival of the patient to the operating room. Blood glucose measurements were taken hourly during the intraoperative period and after admission to our intensive care unit until a stable blood glucose level within the blood glucose target range was achieved. Blood glucose was then checked every 3 hours. Depending on the patient's clinical condition, oral intakes were initiated as soon as possible postoperatively. Intravenous insulin therapy was replaced by subcutaneous insulin when either oral feeding was initiated or 2 days postoperatively.

\section{Pretreatment Variables and Study End Point}

The effect of BIMA was adjusted for the following 20 pretreatment variables: age, female gender, New York Heart Association functional class III to IV, prior myocardial infarction prior percutaneous coronary intervention (PCI), diabetes mellitus, current smoking, chronic obstructive pulmonary disease, cerebrovascular accident, peripheral vascular disease (PVD), history of atrial fibrillation, number of vessels diseased, left main stem disease, left ventricular ejection fraction (LVEF) $<50 \%$, renal impairment defined as a serum creatinine $>200 \mathrm{mmol} / \mathrm{L}$, obesity defined as body mass index $\geq 30$, urgent/emergent indication, preoperative use of intra-aortic balloon pump, surgery performed by a resident physician, and the use of cardiopulmonary bypass.
The short-term outcomes investigated were the incidence of superficial sternal wound infection (SSWI) and deep sternal wound infection (DSWI) as defined by the Centers for Disease Control and Prevention, ${ }^{14}$ postoperative cerebrovascular accident, need for renal replacement therapy, reintubation for acute respiratory failure, reexploration for bleeding, postoperative atrial fibrillation, and operative mortality (within 30 days).

Long-term outcomes investigated were all-cause late mortality and need for repeat revascularization, including PCI and/or redo CABG. All-cause death is considered the most robust and unbiased index because no adjudication is required, thus avoiding inaccurate or biased documentation and clinical assessments. ${ }^{15}$

\section{Statistical Analysis}

The authors adhered to guidelines ${ }^{16}$ for reporting observational studies. For baseline characteristics, variables are summarized as mean for continuous variables and proportion for categorical variables.

Multiple imputation using bootstrapping-based expectation-maximization algorithm was used to address missing data. ${ }^{17}$ To control for measured potential confounders in the data set, PS was generated for each patient from a multivariable logistic regression model based on 20 pretreatment covariates as independent variables with treatment type (BIMA vs SIMA) as a binary dependent variable. ${ }^{18}$ The resulting propensity score represented the probability of a patient undergoing CABG with BIMA grafting. Pairs of patients receiving BIMA and SIMA were derived using greedy 1:1 matching with a calliper of width of 0.2 standard deviation of the logit of the PS. ${ }^{7}$ The quality of the match was assessed by comparing selected pretreatment variables in the PS-matched patient using the standardized mean difference, by which an absolute standardized difference $>10 \%$ is suggested to represent meaningful covariate imbalance. ${ }^{6}$ Analytic methods for the estimation of the treatment effect in the matched sample included McNemar's test to compare proportions. Kaplan-Meier survival curves between treated and untreated subjects in the matched sample were compared using a test described by Klein and Moeschberger. 6,19

$\mathrm{R}$ version 3.1.0 ( $\mathrm{R}$ Foundation for Statistical Computing, Vienna, Austria) was used for statistical analysis.

\section{RESULTS}

The study population consisted of 4195 patients undergoing CABG using SIMA $(\mathrm{n}=3445 ; 78.3 \%)$ or BIMA $(\mathrm{n}=750 ; 21.7 \%)$. In the BIMA group, the right internal mammary artery was used as in situ graft to the LAD in 456 cases. Among those, the left internal mammary artery was used as in situ graft to the circumflex territory. A total of 165 patients had the right internal mammary artery grafted as in situ conduit to the circumflex territory through the transverse sinus. The right internal mammary artery was used as $\mathrm{Y}$ graft to the circumflex territory in 90 cases and as free graft to the right coronary artery in 39 cases. In the BIMA group, BIMAs were harvested as pedicled conduits in 299 out of 750 patients $(40 \%)$ and as skeletonized conduits in the remaining 451 out of 750 patients $(60 \%)$. In the SIMA group, skeletonized technique was used in 1293 out of 3445 patients $(37.5 \%)$.

\section{Missing Data}

The fraction missing ranged from $0 \%$ (age) to $0.8 \%$ (body mass index). Pattern of missingness in the data were 44 and rows after listwise deletion were 3977 . Rows after imputation were 4195 . 
TABLE 1. Pretreatment variables before and after matching in the bilateral internal mammary artery (BIMA) and single internal mammary artery (SIMA) groups

\begin{tabular}{|c|c|c|c|c|c|c|c|c|c|c|}
\hline Variable & BIMA & $=750)$ & SIMA unn & $n=3445)$ & $P$ value & SMD & SIMA m & $n=750)$ & $P$ value & SMD \\
\hline Rge $(y)$ & & & & & & & & & .4 & 3 \\
\hline $22-50$ & 108 & 14.4 & 136 & 3.9 & & & 107 & 14.3 & & \\
\hline $50-60$ & 252 & 33.6 & 546 & 15.8 & & & 250 & 33.3 & & \\
\hline $60-70$ & 268 & 35.7 & 1098 & 31.9 & & & 234 & 31.2 & & \\
\hline $70-80$ & 109 & 14.5 & 1379 & 40.0 & & & 140 & 18.7 & & \\
\hline $80-92$ & 13 & 1.7 & 286 & 8.3 & & & 19 & 2.5 & & \\
\hline Female & & & & & $<.001$ & 28 & & & .8 & 1 \\
\hline No & 669 & 89.2 & 2713 & 78.8 & & & 673 & 89.7 & & \\
\hline Yes & 81 & 10.8 & 732 & 21.2 & & & 77 & 10.3 & & \\
\hline NYHA functional class III-IV & & & & & $<.001$ & 26 & & & 1 & 0 \\
\hline No & 601 & 80.1 & 2367 & 68.7 & & & 601 & 80.1 & & \\
\hline Yes & 149 & 19.9 & 1078 & 31.3 & & & 149 & 19.9 & & \\
\hline MI & & & & & .39 & 4 & & & .75 & 2 \\
\hline No & 448 & 59.7 & 1997 & 58.0 & & & 441 & 58.8 & & \\
\hline Yes & 302 & 40.3 & 1448 & 42.0 & & & 309 & 41.2 & & \\
\hline PCI & & & & & .005 & 11 & & & .63 & 3 \\
\hline No & 617 & 82.3 & 2973 & 86.3 & & & 625 & 83.3 & & \\
\hline Yes & 133 & 17.7 & 472 & 13.7 & & & 125 & 16.7 & & \\
\hline Smoking & & & & & .09 & 7 & & & 1 & 0 \\
\hline No & 660 & 88.0 & 3105 & 90.1 & & & 660 & 88.0 & & \\
\hline Yes & 90 & 12.0 & 340 & 9.9 & & & 90 & 12.0 & & \\
\hline COPD & & & & & .002 & 10 & & & 1 & 0 \\
\hline No & 692 & 92.3 & 3080 & 89.4 & & & 691 & 92.1 & & \\
\hline Yes & 58 & 7.7 & 365 & 10.6 & & & 59 & 7.9 & & \\
\hline CVA & & & & & $<.001$ & 18 & & & .74 & 2 \\
\hline No & 729 & 97.2 & 3212 & 93.2 & & & 732 & 97.6 & & \\
\hline Yes & 21 & 2.8 & 233 & 6.8 & & & 18 & 2.4 & & \\
\hline PVD & & & & & .008 & 11 & & & .82 & 1 \\
\hline No & 703 & 93.7 & 3121 & 90.6 & & & 706 & 94.1 & & \\
\hline Yes & 47 & 6.3 & 324 & 9.4 & & & 44 & 5.9 & & \\
\hline $\mathrm{AF}$ & & & & & .08 & 8 & & & .31 & 6 \\
\hline No & 735 & 98.0 & 3332 & 96.7 & & & 728 & 97.1 & & \\
\hline Yes & 15 & 2.0 & 113 & 3.3 & & & 22 & 2.9 & & \\
\hline LMD & & & & & .08 & 7 & & & .43 & 4 \\
\hline No & 505 & 67.3 & 2432 & 70.6 & & & 520 & 69.3 & & \\
\hline Yes & 245 & 32.7 & 1013 & 29.4 & & & 230 & 30.7 & & \\
\hline NVD & & & & & .03 & 8 & & & .96 & 0 \\
\hline 1 & 15 & 2.0 & 78 & 2.3 & & & 20 & 2.7 & & \\
\hline 2 & 203 & 27.1 & 770 & 22.4 & & & 192 & 25.6 & & \\
\hline 3 & 532 & 70.9 & 2597 & 75.4 & & & 538 & 71.7 & & \\
\hline LVEF $<50 \%$ & & & & & $<.001$ & 23 & & & .76 & 2 \\
\hline No & 651 & 86.8 & 2685 & 77.9 & & & 646 & 86.1 & & \\
\hline Yes & 99 & 13.2 & 760 & 22.1 & & & 104 & 13.9 & & \\
\hline $\mathrm{BMI} \geq 30$ & & & & & .003 & 16 & & & .53 & 4 \\
\hline No & 521 & 69.5 & 2152 & 62.5 & & & 535 & 71.4 & & \\
\hline Yes & 229 & 30.5 & 1293 & 37.5 & & & 215 & 28.6 & & \\
\hline Creatinine $\geq 200 \mu \mathrm{mol} / \mathrm{L}$ & & & & & .059 & 8 & & & .51 & 4 \\
\hline No & 737 & 98.3 & 3339 & 96.9 & & & 741 & 98.8 & & \\
\hline Yes & 13 & 1.7 & 106 & 3.1 & & & 9 & 1.2 & & \\
\hline DM & & & & & $<.001$ & 37 & & & .83 & 1 \\
\hline No & 631 & 84.1 & 2359 & 68.5 & & & 635 & 84.7 & & \\
\hline Yes & 119 & 15.9 & 1086 & 31.5 & & & 115 & 15.3 & & \\
\hline Preoperative IABP & & & & & .04 & 9 & & & .22 & 7 \\
\hline No & 734 & 97.9 & 3317 & 96.3 & & & 741 & 98.8 & & \\
\hline Yes & 16 & 2.1 & 128 & 3.7 & & & 9 & 1.2 & & \\
\hline
\end{tabular}


TABLE 1. Continued

\begin{tabular}{|c|c|c|c|c|c|c|c|c|c|c|}
\hline \multirow{2}{*}{$\begin{array}{l}\text { Variable } \\
\text { Urgent/emergent }\end{array}$} & \multicolumn{2}{|c|}{ BIMA $(n=750)$} & \multicolumn{2}{|c|}{ SIMA unmatched $(n=3445)$} & \multirow{2}{*}{$\frac{P \text { value }}{.01}$} & \multirow{2}{*}{$\frac{\text { SMD }}{10}$} & \multicolumn{2}{|c|}{ SIMA matched $(n=750)$} & \multirow{2}{*}{$\frac{P \text { value }}{.68}$} & \multirow{2}{*}{$\frac{\text { SMD }}{2}$} \\
\hline & & & & & & & & & & \\
\hline No & 536 & 71.5 & 2296 & 66.6 & & & 544 & 72.5 & & \\
\hline Yes & 214 & 28.5 & 1149 & 33.4 & & & 206 & 27.5 & & \\
\hline Resident performing procedure & & & & & $<.001$ & 21 & & & .73 & 2 \\
\hline No & 536 & 71.5 & 2128 & 61.8 & & & 529 & 70.5 & & \\
\hline Yes & 214 & 28.5 & 1317 & 38.2 & & & 221 & 29.5 & & \\
\hline $\mathrm{CPB}$ & & & & & $<.001$ & 15 & & & .77 & 2 \\
\hline No & 538 & 71.7 & 2235 & 64.9 & & & 544 & 72.5 & & \\
\hline Yes & 212 & 28.3 & 1210 & 35.1 & & & 206 & 27.5 & & \\
\hline
\end{tabular}

Values are given as n (\%). SMD, Standardized mean difference; NYHA, New York Heart Association; $M I$, myocardial infarction; $P C I$, percutaneous coronary intervention; $C O P D$, chronic obstructive pulmonary disease; $C V A$, cerebrovascular accident; $P V D$, peripheral vascular disease; $A F$, atrial fibrillation; $L M D$, left main disease; $N V D$, number of vessels diseased; $L V E F$, left ventricular ejection fraction; $B M I$, body mass index; $D M$, diabetes mellitus; $I A B P$, intra-aortic balloon pump; $C P B$, cardiopulmonary bypass; $B I M A$, bilateral internal mammary arteries; SIMA, single internal mammary artery.

\section{PS Matching}

Table 1 summarizes for each pretreatment variable as well as the unmatched and matched means for the treatment group and control group with relative $P$ value and standardized

TABLE 2. Postoperative complications in the matched bilateral internal mammary artery (BIMA) and single internal mammary artery (SIMA) groups

\begin{tabular}{|c|c|c|c|c|c|}
\hline$\frac{\text { Complication }}{30-\mathrm{d} \text { death }}$ & \multicolumn{2}{|c|}{$\begin{array}{l}\text { Matched BIMA } \\
\quad(\mathbf{n}=\mathbf{7 5 0})\end{array}$} & \multicolumn{2}{|c|}{$\begin{array}{c}\text { Matched SIMA } \\
\quad(\mathbf{n}=\mathbf{7 5 0})\end{array}$} & $\begin{array}{c}P \\
\text { value }\end{array}$ \\
\hline No & 745 & 99.3 & 741 & 98.8 & .28 \\
\hline Yes & 5 & 0.7 & 9 & 1.2 & \\
\hline \multicolumn{6}{|l|}{ SSWI } \\
\hline No & 708 & 94.4 & 737 & 98.3 & .0001 \\
\hline Yes & 42 & 5.6 & 13 & 1.7 & \\
\hline \multicolumn{6}{|l|}{ DSWI } \\
\hline No & 734 & 97.9 & 739 & 98.5 & .43 \\
\hline Yes & 16 & 2.1 & 11 & 1.5 & \\
\hline \multicolumn{6}{|l|}{ Postoperative CVA } \\
\hline No & 742 & 98.9 & 748 & 99.7 & .11 \\
\hline Yes & 8 & 1.1 & 2 & 0.3 & \\
\hline \multicolumn{6}{|l|}{ Postoperative RRT } \\
\hline No & 732 & 97.6 & 722 & 96.3 & .17 \\
\hline Yes & 18 & 2.4 & 28 & 3.7 & \\
\hline \multicolumn{6}{|l|}{ POAF } \\
\hline No & 619 & 82.5 & 604 & 80.5 & .35 \\
\hline Yes & 131 & 17.5 & 146 & 19.5 & \\
\hline \multicolumn{6}{|l|}{ Reintervention } \\
\hline No & 727 & 96.9 & 731 & 97.5 & .63 \\
\hline Yes & 23 & 3.1 & 19 & 2.5 & \\
\hline \multicolumn{6}{|l|}{ Reexploration } \\
\hline No & 718 & 95.7 & 720 & 96.0 & .88 \\
\hline Yes & 32 & 4.3 & 30 & 4.0 & \\
\hline \multicolumn{6}{|l|}{ Hospital stay (d) } \\
\hline$<9$ & 581 & 77.5 & 597 & 79.6 & .34 \\
\hline$\geq 9$ & 169 & 22.5 & 153 & 20.4 & \\
\hline
\end{tabular}

Values are given as $\mathrm{n}(\%)$. SSWI, Superficial sternal wound infection; $D S W I$, deep sternal wound infection; $C V A$, cerebrovascular accident; $R R T$, renal replacement therapy; $P O A F$, postoperative atrial fibrillation; BIMA, bilateral internal mammary arteries; SIMA, single internal mammary artery. mean difference. Before matching, patients receiving SIMA were significantly different from those receiving BIMA; overall, 13 out of 20 pretreatment covariates showed standardized mean difference $\geq 10 \%$. Overall, patients receiving SIMA presented a higher risk profile. As expected, patients receiving BIMA were less likely to be operated on by resident physicians. PS matching created a total of 750 matching sets. After matching, all covariates were well balanced between the 2 groups, with standardized mean difference $<10 \%$ for all pretreatment variables.

\section{Short-Term Outcomes}

Table 2 shows the rate of postoperative complications and operative mortality (within 30 days) in the matched sample. The BIMA group was associated with an increased rate of SSWI $(5.6 \%$ vs $1.7 \% ; P=.0001)$ but the incidence of DSWI was comparable between the 2 groups, at $2.1 \%$ and $1.5 \%$ in the BIMA and SIMA groups, respectively $(P=.43)$. Pedicled internal mammary artery was used in $299(39 \%)$ and $266(35 \%)$ in the BIMA and SIMA groups, respectively. Among patients receiving pedicled internal mammary artery, the incidence of SSWI was 23 out of $299(7.6 \%)$ and 5 out of $266(1.8 \%)$ in the BIMA and SIMA groups, respectively $(P=.002)$ and the incidence of DSWI was 12 out of $299(4.0 \%)$ and 6 out of 266 $(2.2 \%)$ in the BIMA and SIMA groups, respectively $(P=.34)$. Skeletonized internal mammary artery was used in $451(60.1 \%)$ and $484(64.5 \%)$ patients in the BIMA and SIMA groups, respectively. Among patients receiving a skeletonized internal mammary artery, the incidence of SSWI was 19 out of $451(4.2 \%)$ and 8 out of $484(1.6 \%)$ in the BIMA and SIMA groups, respectively $(P=.03)$ and the incidence of DSWI was 4 out of 451 $(0.9 \%)$ and 5 out of $484(1.0 \%)$ in the BIMA and SIMA groups, respectively $(P=1)$. Overall, skeletonized BIMA was associated with a significant reduction in the incidence of SSWI $(P=.04)$ and DSWI $(P=.004)$ when compared with pedicled BIMA (Figure 1). 


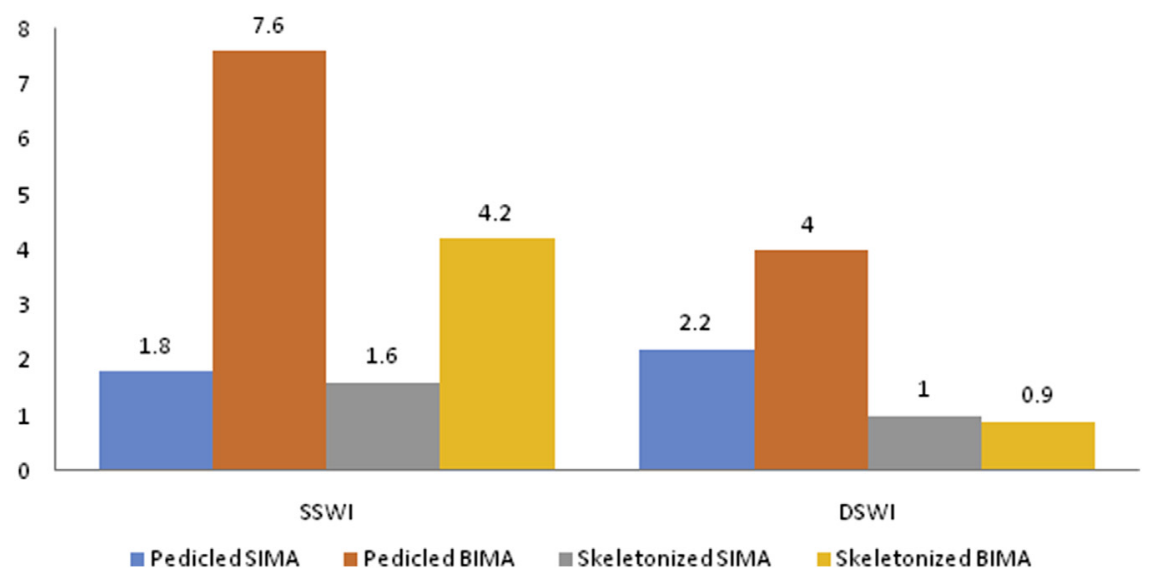

FIGURE 1. Incidence of superficial sternal wound infection (SSWI) and deep sternal wound infection (DSWI) in the bilateral internal mammary artery $(B I M A)$ and single internal mammary artery (SIMA) groups, respectively, according to the harvesting technique.

With regard to other postoperative complications the 2 groups were comparable. Operative mortality rate did not significantly differ between the 2 groups, with $0.7 \%$ and $1.2 \%$ in the BIMA and SIMA groups, respectively $(P=.28)$.

Total number of grafts per patients was slightly higher in the BIMA group (2.88 grafts per patient) than in the SIMA group (2.74 grafts per patient) $(P=.01)$.

\section{Long-Term Outcomes}

In the matched sample, the mean follow-up time was $4.8 \pm 3.2$ years (maximum, 12 years). A total of 75 late deaths were recorded, including 28 patients in the BIMA group and 47 patients in the SIMA group, respectively. Survival probability was $98.1 \% \pm 0.5 \%$ versus $96.6 \% \pm 0.6 \%$

Survival

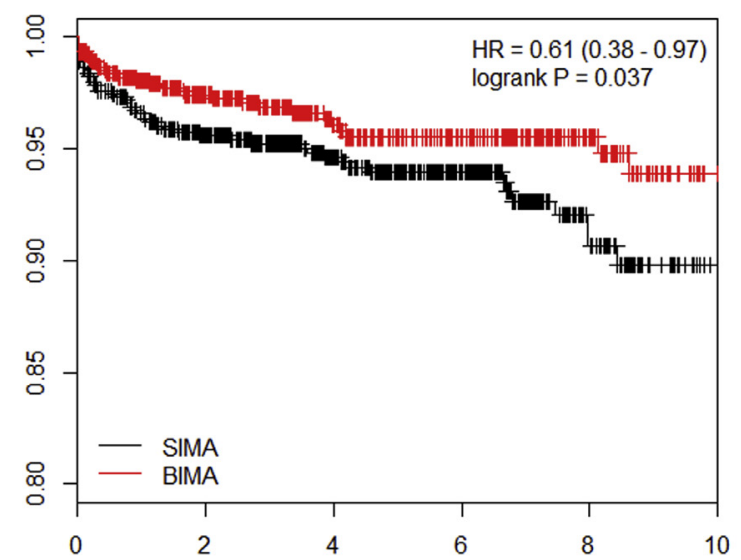

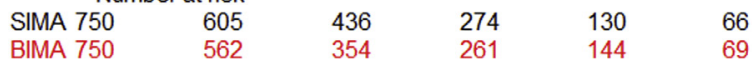

at 1 year, $95.5 \% \pm 0.8 \%$ versus $93.8 \% \pm 0.9 \%$ at 5 years, and $93.9 \% \pm 1.4 \%$ versus $89.8 \% \pm 1.8 \%$ at 10 years in the BIMA and SIMA groups, respectively. Compared with SIMA, BIMA was associated with a significantly lower risk for late mortality (hazard ratio, $0.61 ; 95 \%$ confidence interval, $0.38-0.97 ; P=.03$ ) with an absolute risk reduction of $39 \%$ (Figure 2, left). A total of 128 patients required repeat revascularization, including 53 cases in the BIMA group and 75 cases in the SIMA group. Repeat revascularization free survival probability was $96.5 \% \pm 0.6 \%$ versus $95.1 \% \pm 0.7 \%$ at 1 year, $91.8 \% \pm 1.1 \%$ versus $90.2 \% \pm 1.2 \%$ at 5 years, and $87.9 \% \pm 2.0 \%$ versus $83.6 \% \pm 2.2 \%$ at 10 years in the BIMA and SIMA groups, respectively. Compared with SIMA, BIMA was associated with a significantly lower rate of repeat revascularization

\section{Repeat revascularization free survival}

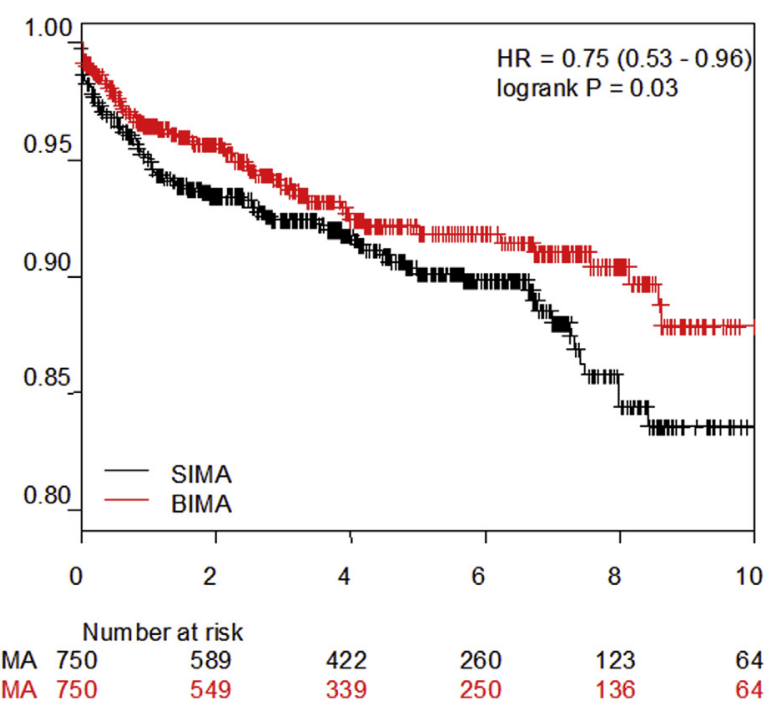

FIGURE 2. Left, Kaplan-Meier curves for overall survival. Right, repeat revascularization-free survival in the propensity score matched bilateral internal mammary artery (BIMA) and single internal mammary artery (SIMA) groups. HR, Hazard ratio. 


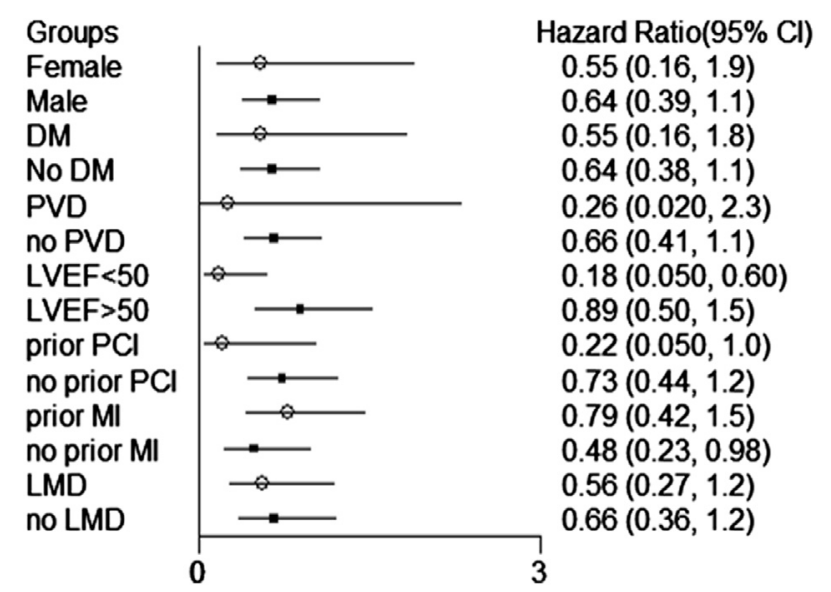

FIGURE 3. Hazard ratio and $95 \%$ confidence interval $(C I)$ for long-term mortality using bilateral internal mammary arteries and single internal mammary artery, according to the presence of cardiovascular risk factors, including diabetes mellitus $(D M)$, peripheral vascular disease $(P V D)$, left ventricular ejection fraction $(L V E F)$, percutaneous coronary intervention $(P C I)$, myocardial infarction $(M I)$, and left main disease $(L M D)$.

(hazard ratio, $0.75 ; 95 \%$ confidence interval, 0.53-0.96; $P=.03)$ with an absolute risk reduction of $25 \%$ (Figure 2, right). In a subgroup analysis (Figure 3), BIMA was protective for late survival over SIMA regardless of the presence of main cardiovascular risk factors, although a trend toward an extra benefit was confirmed in patients with LVEF $<50 \%$, PVD, and previous PCI.

\section{DISCUSSION}

The main finding of our single-center PS matching comparison was that when compared to SIMA grafting, BIMA use was associated with comparable short-term outcomes, including the incidence of DSWI, but a significantly lower rate of repeat revascularization and better long-term survival regardless of the presence of main cardiovascular risk factors.

Despite increasing evidence from observational cohort studies that suggest long-term survival advantages for patients receiving BIMA grafts, only few patients currently undergo this operation. The most often cited reason reported by cardiac surgeons is the lack of definitive evidence for long-term benefit from BIMA $^{13}$ and the perception that BIMA is associated with increased early morbidity and mortality, ${ }^{12}$ specifically the occurrence of DSWI and the well-documented increased risk of death that accompanies it. ${ }^{13}$ Only 1 randomized trial investigating long-term outcomes in patients receiving BIMA $^{3}$ is currently underway and results should be available by 2018 .

PS matching by creating a quasirandomized study design is increasingly being used in retrospective analyses ${ }^{5}$ to minimize the influence of any imbalance in pretreatment patient characteristics that affect treatment selection. ${ }^{6,7}$
However, a recent systematic review on BIMA versus SIMA found that only 4 out of 27 observational studies using PS matching demonstrated a survival benefit from BIMA. $^{8-11}$ Locker and colleagues $^{20}$ recently conducted a PS matching between patients receiving multiple arterial grafts, including BIMA, and patients receiving SIMA, showing a survival advantage from BIMA. However the multiple arterial graft group included patients receiving the radial artery alone or in combination with a second internal mammary artery. This aspect limits the possibility to extrapolate the effect of BIMA per se over SIMA on long-term survival.

Recently several recommendations have been made about conducting PS matching. ${ }^{5-7}$ For meaningful conclusions, authors reporting on PS matching comparisons are required to provide sufficient and clear information on how the PS was developed, the handling of missing data, how was the PS-matched sample was created, how balance between treatment groups was assessed, and the statistical methods used to estimate the treatment effect.

We performed a PS matching comparison between BIMA over SIMA grafting adhering to current recommendations on PS matching. ${ }^{5-7}$ BIMA use was found to not increase operative mortality and the incidence of major postoperative complications, including the incidence of DSWI. This was particularly evident when the skeletonized technique was used to harvest the internal mammary arteries. There is still controversy on the detrimental effect of BIMA use on the incidence of sternal wound infection. A recent report ${ }^{21}$ that included a large number of patients failed to confirm BIMA use as an independent risk factor for DSWI and our results challenge the general notion that routine BIMA use predisposes patients to increased risk of DSWI in particular when the internal mammary arteries are harvested as skeletonized conduit. ${ }^{22}$ Furthermore, it is difficult to assess the effect of BIMA harvesting in isolation because there was apparently little standardization of practice in relation to stabilization of the sternum. In our study the use of BIMA was only found to significantly increase the incidence of SSWI even if such a detrimental effect was mitigated by the use of skeletonized conduits.

With regard to long-term outcomes, we found that BIMA use was associated with a significantly lower rate of repeat revascularization and late death. The better patency rate observed with BIMA use over SVG may partially explain the observed long-term survival benefit. ${ }^{23}$ In addition, the use of arterial conduits has been associated with a reduced atherosclerotic progression in the native coronary vessels ${ }^{24}$ that might have partially contributed to the better survival observed among patients receiving BIMA. BIMA was found to be protective for late death regardless of the presence of main cardiovascular risk factors, although an extra survival benefit was observed among high-risk 
subgroups such as patients with LVEF $<50 \%$, PVD, and previous PCI. There has been reluctance to use BIMA in patients at higher operative risk such as those with left ventricular dysfunction. ${ }^{25}$ Our study supports the use of BIMA grafting among patients with left ventricular systolic dysfunction because it may provide enhanced long-term survival thus supporting other reports. ${ }^{26}$ Finally, the occurrence of stent failure as well as the evidence of PVD can identify a subset of patients with particularly aggressive coronary atherosclerosis. Venous grafts have a high incidence of failure among these patients, ${ }^{27}$ whereas arterial conduits have been shown to improve angiographic and clinical results. Therefore arterial grafts, including BIMA, should probably be considered as the first surgical choice in this patient population.

The principal limitation of our analysis is the inability to address hidden biases due to unobserved or unrecorded differences between treated and control patients before treatment. As a consequence our results could reflect the effects of unknown or unmeasured confounders. Moreover, we were unable to provide specific causes of death (cardiac vs noncardiac) and therefore we can only speculate that the mechanism beyond the better long-term survival observed in our BIMA group is related to the better patency rate of the second internal mammary artery over SVG. ${ }^{2.3}$

\section{CONCLUSIONS}

When compared with SIMA grafting, BIMA use did not increase the incidence of operative complications, including DSWI, and improved long-term overall survival and repeat revascularization-free survival. According to our results BIMA grafting should be strongly recommended in patients undergoing surgical myocardial revascularization.

\section{References}

1. Lytle BW, Blackstone EH, Loop FD, Houghtaling PL, Arnold JH, Akhrass R, et al. Two internal thoracic artery grafts are better than one. J Thorac Cardiovasc Surg. 1999;117:855-72.

2. Weiss AJ, Zhao S, Tian DH, Taggart DP, Yan TD. A meta-analysis comparing bilateral internal mammary artery with left internal mammary artery for coronary artery bypass grafting. Ann Cardiothorac Surg. 2013;2:390-400.

3. Taggart DP, Altman DG, Gray AM, Lees B, Nugara F, Yu LM, et al. Randomized trial to compare bilateral vs. single internal mammary coronary artery bypass grafting: 1-year results of the Arterial Revascularisation Trial (ART). Eur Heart J. 2010;31:2470-81.

4. Blackstone EH. Comparing apples and oranges. J Thorac Cardiovasc Surg. $2002 ; 123: 8-15$

5. Collins GS, Le Manach Y. Comparing treatment effects between propensity scores and randomized controlled trials: improving conduct and reporting. Eur Heart J. 2012;33:1867-9.

6. Austin PC. A tutorial and case study in propensity score analysis: an application to estimate the effect of in-hospital smoking cessation counseling on mortality. Multivariate Behav Res. 2011;46:119-51.
7. Austin PC. A comparison of 12 algorithms for matching on the propensity score. Stat Med. 2014;33:1057-69.

8. Lytle BW, Blackstone EH, Sabik JF, Houghtaling P, Loop FD, Cosgrove DM. The effect of bilateral internal thoracic artery grafting on survival during 20 postoperative years. Ann Thorac Surg. 2004;78:2005-12.

9. Kurlansky PA, Traad EA, Dorman MJ, Galbut DL, Zucker M, Ebra G. Thirty-year follow-up defines survival benefit for second internal mammary artery in propensity-matched groups. Ann Thorac Surg. 2010;90:101-8.

10. Grau JB, Ferrari G, Mak AW, Shaw RE, Brizzio ME, Mindich BP, et al Propensity matched analysis of bilateral internal mammary artery versus single left internal mammary artery grafting at 17 -year follow up: validation of a contemporary surgical experience. Eur J Cardiothorac Surg. 2012;41: 770-5.

11. Kinoshita T, Asai T, Suzuki T, Kuroyanagi S, Hosoba S, Takashima N. Off-pump bilateral skeletonized internal thoracic artery grafting in elderly patients. Ann Thorac Surg. 2012;93:531-6.

12. Légaré JF, Buth KJ, Sullivan JA, Hirsch GM. Composite arterial grafts versus conventional grafting for coronary artery bypass grafting. J Thorac Cardiovasc Surg. 2004;127:160-6.

13. Dai C, Lu Z, Zhu H, Xue S, Lian F. Bilateral internal mammary artery grafting and risk of sternal wound infection: evidence from observational studies. Ann Thorac Surg. 2013;95:1938-45.

14. Garner JS, Jarvis WR, Emori TG, Horan TC, Hughes JM. CDC definitions for nosocomial infections, 1988. Am J Infect Control. 1988;16:128-40.

15. Lauer MS, Blackstone EH, Young JB, Topol EJ. Cause of death in clinical research: time for a reassessment? J Am Coll Cardiol. 1999;34: 618-20.

16. von Elm E, Altman DG, Egger M, Pocock SJ, Gøtzsche PC, Vandenbroucke JP Strengthening the reporting of observational studies in epidemiology (STROBE) statement: guidelines for reporting observational studies. BMJ 2007;335:806.

17. James H, Gary K, Matthew B. Amelia II: a program for missing data. 2011. Available at: http://www.icesi.edu.co/CRAN/web/packages/Amelia/vignettes/amelia. pdf. Accessed April 1, 2014.

18. Stampf S. Propensity score based data analysis using non-random. 2011. Available at: ftp://ftp.yz.yamagata-u.ac.jp/pub/cran/web/packages/nonrandom/ vignettes/nonrandom.pdf. Accessed April 1, 2014.

19. Therneau T. A package for survival analysis in S. R package version 2.37-4. 2013 Available at: http://CRAN.R-project.org/package=survival. Accessed April 1, 2014

20. Locker C, Schaff HV, Dearani JA, Joyce LD, Park SJ, Burkhart HM, et al Multiple arterial grafts improve late survival of patients undergoing coronary artery bypass graft surgery: analysis of 8622 patients with multivessel disease. Circulation. 2012;126:1023-30.

21. Itagaki S, Cavallaro P, Adams DH, Chikwe J. Bilateral internal mammary artery grafts, mortality and morbidity: an analysis of 1526360 coronary bypass operations. Heart. 2013;99:849-53.

22. Raja SG, Dreyfus GD. Internal thoracic artery: to skeletonize or not to skeletonize? Ann Thorac Surg. 2005;79:1805-11.

23. Benedetto U, Raja SG, Albanese A, Amrani M, Biondi-Zoccai G, Frati G. Searching for the second best graft for coronary artery bypass surgery: a network meta-analysis of randomized controlled trials. Eur J Cardiothorac Surg. March 30, 2014 [Epub ahead of print].

24. Dimitrova KR, Hoffman DM, Geller CM, Dincheva G, Ko W, Tranbaugh RF Arterial grafts protect the native coronary vessels from atherosclerotic disease progression. Ann Thorac Surg. 2012;94:475-81.

25. Mohammadi S, Kalavrouziotis D, Cresce G, Dagenais F, Dumont E Charbonneau E, et al. Bilateral internal thoracic artery use in patients with low ejection fraction: is there any additional long-term benefit? Eur J Cardiothorac Surg. 2014;46:425-31.

26. Galbut DL, Kurlansky PA, Traad EA, Dorman MJ, Zucker M, Ebra G. Bilatera internal thoracic artery grafting improves long-term survival in patients with reduced ejection fraction: a propensity-matched study with 30-year follow-up. J Thorac Cardiovasc Surg. 2012;143:844-53.e4.

27. Gaudino M, Cellini C, Pragliola C, Trani C, Burzotta F, Schiavoni G, et al. Arterial versus venous bypass grafts in patients with in-stent restenosis. Circulation. 2005;112(9 Suppl):I265-9. 